\title{
Expression of concern: "Hassan W, David J (2014) Effect of lead pollution on soil microbiological index under spinach (Spinacia oleracea L.) cultivation. J Soils Sediments 14: 44-59"
}

(C) Springer-Verlag GmbH Germany, part of Springer Nature 2020

The Editors-in-Chief would like to alert readers to the following article published in the Journal of Soils and Sediments:

Effect of lead pollution on soil microbiological index under spinach (Spinacia oleracea L.) cultivation. DOI 10.1007/ s11368-013-0802-3 January 2014, Volume 14, Issue 1, pp. 44-59, Waseem Hassan, Julie David

The Editors-in-Chief would like to alert readers that this article (Hassan and David, 2014) is part of an investigation being conducted by the Muhammad Nawaz Shareef University of Agriculture (MNSUA). Mr. Waseem Hassan has filed a complaint in the Lahore High Court against Muhammad Nawaz Shareef University of Agriculture. Mr.
Hassan claims that he was wrongfully fired from his position as Assistant Professor because he was found guilty of plagiarizing from Mr. Idrees Haider's masters' thesis published in 2009 at PMAS Arid Agriculture University, Rawalpindi, Pakistan.

An update will be provided once a resolution has been reached.

None of the authors has agreed to this editorial expression of concern. In addition, the identity of Julie David was never verified. 